\title{
The Effect of Sex-Mismatched Red Blood Cell Transfusion on Endothelial Cell Activation in Critically III Patients
}

\author{
Abdulrahman Alshalani ${ }^{a, b}$ Lisa van Manen ${ }^{a, c}$ Margit Boshuizen ${ }^{a}$ \\ Robin van Bruggenc Jason P. Acker ${ }^{d, e}$ Nicole P. Juffermans ${ }^{a, f}$ \\ aLaboratory of Experimental Intensive Care and Anesthesiology, Amsterdam UMC, Amsterdam, The Netherlands; \\ bepartment of Clinical Laboratory Sciences, King Saud University, Riyadh, Saudi Arabia; 'Department of Blood \\ Cell Research, Sanquin Research and Landsteiner Laboratory, Academic Medical Center, University of Amsterdam,

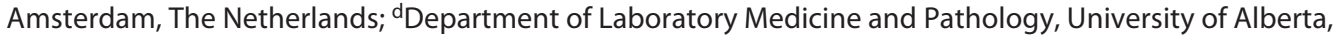 \\ Edmonton, AB, Canada; ${ }^{e}$ Centre for Innovation, Canadian Blood Services, Edmonton, AB, Canada; ${ }^{f}$ Department of \\ Intensive Care, OLVG Hospital, Amsterdam, The Netherlands
}

\section{Keywords}

Sex-mismatched transfusion · Red blood cell · Blood donor · Transfusion outcomes · Endothelial activation · Critically ill patients

\begin{abstract}
Background: Observational studies suggest that sex-mismatched transfusion is associated with increased mortality. Mechanisms driving mortality are not known but may include endothelial activation. The aim of this study is to investigate the effects of sex-mismatched red blood cell (RBC) transfusions on endothelial cell activation markers in critically ill patients. Study Design and Methods: In patients admitted to the intensive care unit who received a single RBC unit, blood samples were drawn before $\left(T_{0}\right), 1 \mathrm{~h}$ after $\left(T_{1}\right)$, and $24 \mathrm{~h}$ after transfusion $\left(\mathrm{T}_{24}\right)$ for analysis of soluble syndecan-1, soluble intercellular adhesion molecule-1, soluble thrombomodulin (sTM), von Willebrand factor antigen, interleukin-6 (IL-6), and tumor necrosis factor-alpha (TNFa). Changes in the levels of these factors were compared between sex-matched and sex-mismatched groups. Results: Of 69 included patients, 32 patients were in the sex-matched and 37 patients were in the sex-mismatched group. Compared to baseline, sex-matched transfusion was associated with significant reduction in STM level ( $p$ value $=0.03$ ). Between-group comparison showed that levels of syndecan-1
\end{abstract}

and STM were significantly higher in the sex-mismatched group compared to the sex-matched group at $\mathrm{T}_{24}(p$ value $=$ 0.04 and 0.01, respectively). Also, TNFa and IL-6 levels showed a statistically marginal significant increase compared to baseline in the sex-mismatched group at $\mathrm{T}_{24}$ ( $p$ value $=0.06$ and 0.05 , respectively), but not in the sex-matched group. Discussion: Transfusion of a single sex-mismatched RBC unit was associated with higher syndecan-1 and STM levels compared to transfusion of sex-matched RBC unit. These findings may suggest that sex-mismatched RBC transfusion is associated with endothelial activation.

\section{(c) 2021 The Author(s).}

Published by S. Karger AG, Basel

\section{Introduction}

Red blood cell (RBC) transfusion is a common lifesaving therapy for patients hospitalized in the intensive care unit (ICU), with nearly half of ICU patients receiving at least one RBC unit during their stay [1-3]. Despite its widespread usage, several studies have linked RBC transfusion to adverse clinical outcomes, particularly in critically ill patients [4-6]. Recently, observational studies using data from various transfusion registries have suggested that donor-specific characteristics may impact patient outcome. More specifically, a mismatch between the sex of blood donors and recipients was found to be associated mercial purposes requires written permission. 
with increased mortality of recipients of RBC transfusions [7-12]; however, results from other studies have been inconsistent [13]. As the majority of studies on the effect of sex-mismatched transfusions have only focused on mortality as the main outcome, specific mechanisms driving transfusion-related mortality are not known.

Critically ill patients often display evidence of endothelial activation, characterized by upregulation of circulating cell adhesion molecules, such as intercellular adhesion molecule-1 (ICAM-1). In addition, there are indications for loss of endothelial glycocalyx integrity, characterized by releasing syndecan- 1 into the circulation [14-18]. It can be hypothesized that in the critically ill patients the presence of an activated endothelium interacts with RBCs, which is in line with previous studies showing that $\mathrm{RBC}$ transfusion is associated with changes in ICAM-1 and syndecan-1 concentrations [19]. A recent study has also shown that blood donor age and sex can impact secretion of endothelial markers after incubating blood product supernatant with endothelial cells [20]. In terms of potential mediators of endothelial activation following RBC transfusion, an increase in levels of circulating inflammatory cytokines, such as interleukin-6 (IL-6) and necrosis factor-alpha (TNF $\alpha)[6,21]$, have been suggested to promote endothelial activation [22]. Other mediators that can induce endothelial activation are the presence of circulating hemoglobin and free heme [2327].

Studying the course of endothelial activation may serve as a predictive marker for adverse outcomes associated with blood transfusion. However, there are currently no data on the effects of donor-recipient, sex-mismatched transfusions on endothelial activation. The aim of this study is to investigate the effects of sex-mismatched transfusion on markers of endothelial activation. We hypothesized that RBC transfusion from sex-mismatched donors to critically ill patients would result in higher levels of circulating endothelial markers compared to sexmatched donors.

\section{Materials and Methods}

\section{Study Design}

This study aims to investigate the effects of RBC transfusion on the host response of patients admitted to the ICU of the Amsterdam University Medical Centre in Amsterdam, the Netherlands. The study cohort was restricted to adult patients who received a single RBC unit to correct anemia (given at a hemoglobin level of $7 \mathrm{~g} / \mathrm{dL}$ ) during their ICU stay. Actively bleeding patients were excluded. Blood donor demographics, including sex, age, weight, and height, in addition to RBC storage duration, were obtained from Sanquin Blood Supply in Amsterdam. These characteristics of the donors were linked to their recipients via a product identification number. All blood donors were at least 18 years old, and all RBC units were leukocyte-depleted and stored in SAGM (saline-adenine-glucose-mannitol) additive solution. The study was divided into two groups, a donor-recipient, sex-matched transfusion group, and a donor-recipient, sex-mismatched transfusion group. Ethical approval of this study was obtained from the Medical Ethical Committee of the Amsterdam Medical Centre, Amsterdam (NTR 6596; NL61833.018.17). Written informed consent was obtained from all participants or their legal representatives.

\section{Blood Sampling and Testing}

Blood samples were drawn from an indwelling arterial catheter into EDTA, citrate, and heparin collection tubes at 3 time points; prior to transfusion $\left(\mathrm{T}_{0}\right), 1 \mathrm{~h}$ after transfusion $\left(\mathrm{T}_{1}\right)$, and $24 \mathrm{~h}$ after transfusion $\left(\mathrm{T}_{24}\right)$. Blood samples were centrifuged at $1,500 \times g$ for $20 \mathrm{~min}$, and the supernatant was frozen at $-80^{\circ} \mathrm{C}$ for further analysis of endothelial activation markers including soluble syndecan-1, soluble ICAM-1, soluble thrombomodulin (sTM), and von Willebrand factor antigen (vWF:Ag). Mediators of endothelial activation included IL-6, TNFa, free $\mathrm{Hb}$, and free heme. Syndecan-1, soluble ICAM-1, sTM, IL-6, and TNFa levels were measured in EDTA plasma with a Luminex ${ }^{\circledR}$ assay (R\&D systems). The percentage of vWF:Ag was measured from citrate plasma using an enzyme-linked immunosorbent assay (ELISA) (R\&D systems). Cell free $\mathrm{Hb}$ and free heme levels were determined from the plasma of heparinized blood using a chromogenic assay (QuantiChrom, Bioassay Systems).

\section{Statistical Analysis}

Data of endothelial activation markers and mediators of endothelial activation were not normally distributed according to Shapiro-Wilk test. Therefore, non-parametric tests were used to compare within/between groups in this study. Due to baseline differences on each outcome at $\mathrm{T}_{0}$, two statistical approaches were applied. A within-group comparison was used to measure differences between pre- and post-transfusion within each group using Friedman analysis of variance at the three time points $\left(\mathrm{T}_{0}, \mathrm{~T}_{1}\right.$, and $\mathrm{T}_{24}$ ). Subsequent pairwise comparisons were performed to identify the contribution of each testing point. Subsequently, a between-groups analysis was used to measure differences between sex-matched and sex-mismatched transfusion groups by generating two timing points of absolute change: from the baseline to $1 \mathrm{~h}$ after transfusion $\left(\Delta \mathrm{T}_{1}\right)$ and from the baseline to $24 \mathrm{~h}$ after transfusion $\left(\Delta \mathrm{T}_{24}\right)$. An independent Mann-Whitney $\mathrm{U}$ test was used to assess between-group differences. Correlation between storage duration and endothelial activation markers were tested using Spearman correlation. Unless stated otherwise, medians and interquartile ranges (IQR) were reported. A $p$ value of less than 0.05 was considered statistically significant. For the pairwise comparisons, reported $p$ values have been adjusted by Bonferroni correction for multiple tests. Statistical analyses were performed using SPSS ${ }^{\circledR}$ version 26.00 software. Graphical representation was generated using GraphPad Prism ${ }^{\circledR}$ version 8.3.0.

\section{Results}

\section{Study Population}

The characteristics of the patients included in this study are summarized in Table 1. Less than half of the patients were female and the median age was 63 years. A little more than half of patients were admitted to ICU for surgical needs, which included cardiac surgery, neurosurgery, and general surgery, while the remaining patients were admitted for specialized medical care in car- 
A

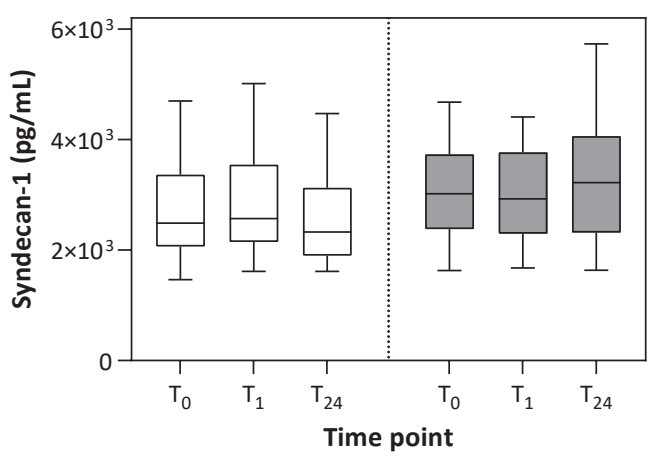

C

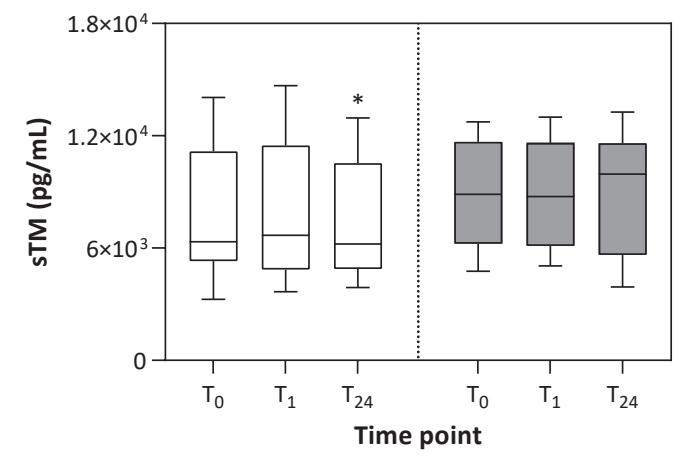

Sex-matched transfusion
B
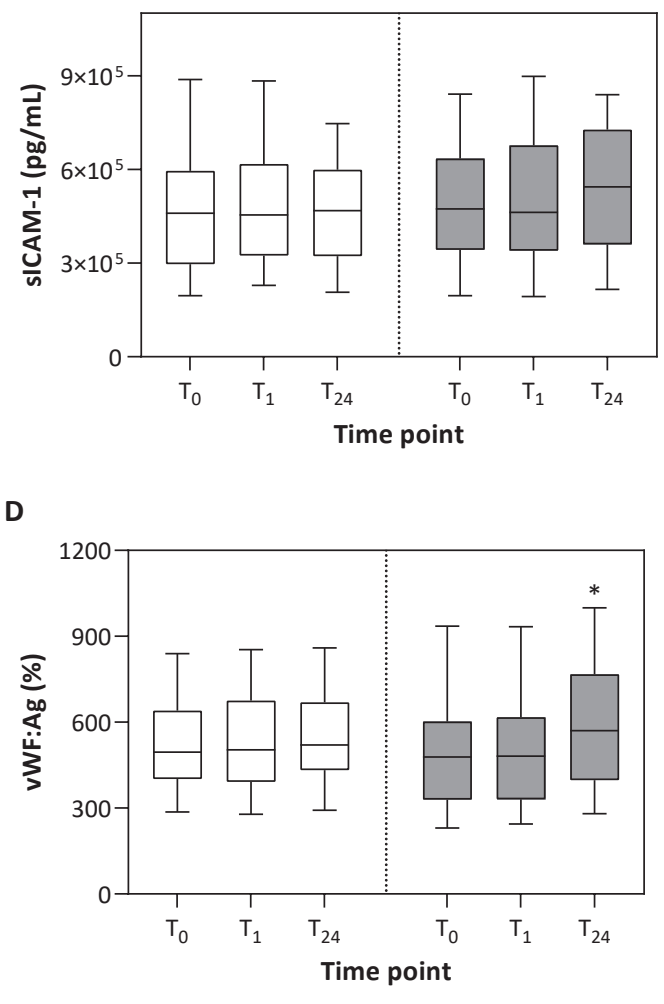

Sex-mismatched transfusion
Fig. 1. Box plots of endothelial activation markers of soluble syndecan-1 (A), soluble ICAM-1 (sICAM-1) (B), soluble thrombomodulin (sTM) (C), and von Willebrand factor antigen (vWF:Ag) (D) of sex-matched and sex-mismatched transfusion prior to transfusion $\left(\mathrm{T}_{0}\right), 1 \mathrm{~h}$ after transfusion $\left(\mathrm{T}_{1}\right)$, and $24 \mathrm{~h}$ after transfu- sion $\left(\mathrm{T}_{24}\right)$. The box at each testing time point represents the interquartile ranges (IQR), the bar inside the box is the median, and the top and bottom of the whiskers represent the full range of the minimum and maximum limit of all of the data. ${ }^{*}$ Significant difference ( $p$ value $<0.05)$ when compared with the baseline testing $\left(\mathrm{T}_{0}\right)$.

Table 1. Characteristics and outcome of critically ill patients receiving either a sex-matched or sex-mismatched transfusion

\begin{tabular}{|c|c|c|c|c|}
\hline & $\begin{array}{l}\text { All patients } \\
(n=69)\end{array}$ & $\begin{array}{l}\text { Sex-matched } \\
\text { transfusion }(n=32)\end{array}$ & $\begin{array}{l}\text { Sex-mismatched } \\
\text { transfusion }(n=37)\end{array}$ & $p$ value \\
\hline \multicolumn{5}{|l|}{ Sex } \\
\hline Female, \% (n) & $43.5(30)$ & $46.9(15)$ & $40.5(15)$ & 0.60 \\
\hline \multicolumn{5}{|l|}{ Age, years } \\
\hline Median (IQR) & $63(57-74)$ & $63.5(51.3-75)$ & $63(59.5-71.5)$ & 0.63 \\
\hline \multicolumn{5}{|l|}{ Ethnicity, \% (n) } \\
\hline Asian & $4.3(3)$ & $3.1(1)$ & $5.4(2)$ & \multirow{3}{*}{0.89} \\
\hline Caucasian & $89.9(62)$ & $90.6(29)$ & $89.2(33)$ & \\
\hline African & $5.8(4)$ & $6.3(2)$ & $5.4(2)$ & \\
\hline \multicolumn{5}{|l|}{ Admission specialty, \% (n) } \\
\hline Medical & $44.9(31)$ & $31.3(10)$ & $56.8(21)$ & \multirow[b]{2}{*}{0.03} \\
\hline Surgical & $55.1(38)$ & $68.8(22)$ & $43.2(16)$ & \\
\hline \multicolumn{5}{|l|}{ SOFA score at admission } \\
\hline Median (IQR) & $8(6.5-11)$ & $8(7-10.8)$ & $7(5-11)$ & 0.33 \\
\hline \multicolumn{5}{|l|}{ Duration of ICU stay, days } \\
\hline Median (IQR) & $11(3.3-16.8)$ & $11(4-19)$ & $11(3-16)$ & 0.69 \\
\hline ICU mortality, \% (n) & $24.6(17)$ & $28.1(9)$ & $21.6(8)$ & 0.53 \\
\hline
\end{tabular}

SOFA, sequential organ failure assessment score. 
A

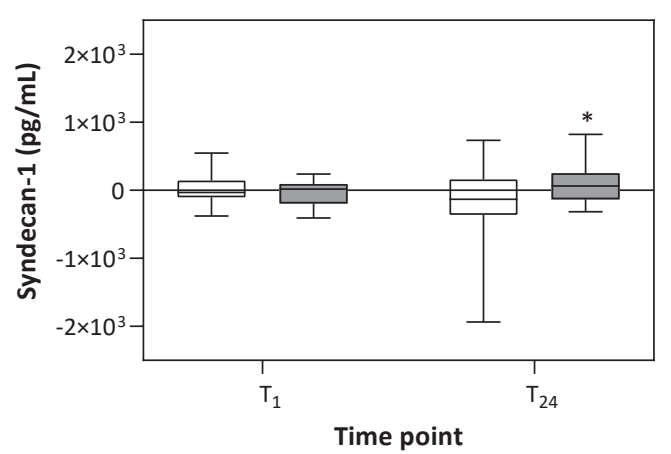

C

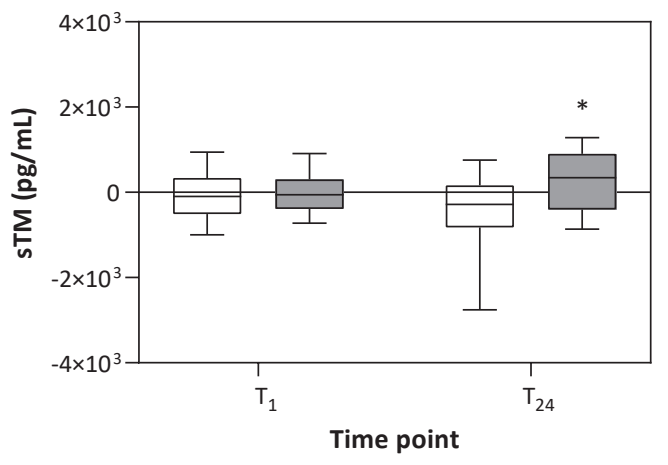

Sex-matched transfusion
B

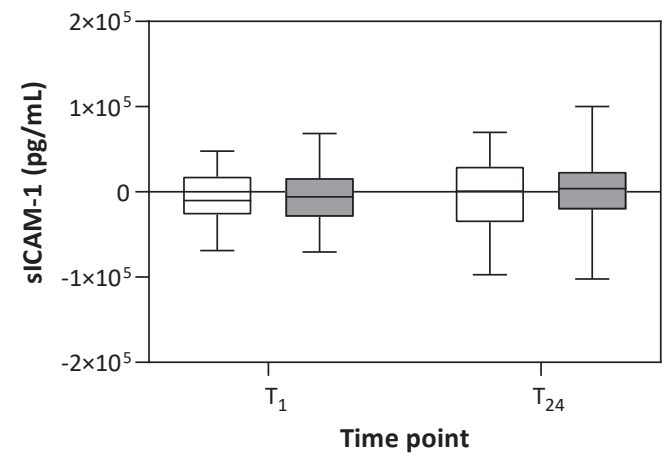

D

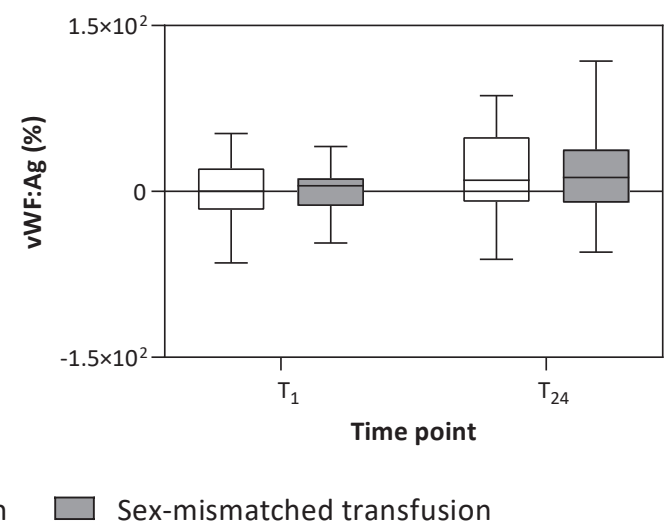

Fig. 2. Post-transfusion differences between sex-matched and sexmismatched groups of endothelial markers of soluble syndecan-1 (A), soluble ICAM-1 (sICAM-1) (B), soluble thrombomodulin (sTM) (C), and von Willebrand factor antigen (vWF:Ag) (D). $\Delta \mathrm{T}_{1}$ is the difference between the baseline testing $\left(\mathrm{T}_{0}\right)$ and $1 \mathrm{~h}$ after transfusion $\left(\mathrm{T}_{1}\right) \cdot \Delta \mathrm{T}_{24}$ is the difference between the baseline testing $\left(\mathrm{T}_{0}\right)$ and $24 \mathrm{~h}$ after transfusion $\left(\mathrm{T}_{24}\right)$. Zero line represents no change from $\mathrm{T}_{0}$. The box at each testing time point represents the interquartile ranges (IQR), the band inside the box is the median, and the top and bottom of the whiskers represent the full range of the minimum and maximum limit of all of the data. * Significant difference ( $p$ value $<0.05$ ) between sex-matched and sex-mismatched groups.

age of 49 years (IQR, 36.8-56.3). Storage duration of blood used in transfusions did not differ between groups (13 days, IQR, 6.5-23).

\section{Effects of Sex-Mismatched Transfusion on Endothelial} Activation Markers

Figure 1 shows the box plot of endothelial activation markers: soluble syndecan-1, sICAM-1, sTM, and vWF:Ag. There was a significant decrease of sTM over time in the sex-matched transfusion group between $6.3 \times$ $10^{3} \mathrm{pg} / \mathrm{mL}\left(\mathrm{IQR}, 5.3-11.2 \times 10^{3}\right)$ at $\mathrm{T}_{0}$ to $6.2 \times 10^{3} \mathrm{pg} / \mathrm{mL}$ $\left(\mathrm{IQR}, 4.8-10.5 \times 10^{3}\right)$ at $\mathrm{T}_{24}(p$ value $=0.02)$. This decline was not noted in the sex-mismatched transfusion group ( $p$ value $=0.76$ ). Additionally, the percentage of vWF:Ag significantly increased over time in the sex-mismatched transfusion group from $442 \%$ (IQR, 326.3-583.3) at $\mathrm{T}_{0}$ to $524 \%(\mathrm{IQR}, 372.5-603.5)$ at $\mathrm{T}_{24}(p$ value $=0.03)$, and there was a marginally significant increase in the sex-matched 
transfusion group from $495 \%$ (IQR, 401-640) at $\mathrm{T}_{0}$ to $520 \%(\mathrm{IQR}, 432-669.5)$ at $\mathrm{T}_{24}(p$ value $=0.06)$. Soluble syndecan-1 and sICAM-1 showed no significant difference within groups over time.

Differences between groups were compared using the absolute change from baseline to either $1 \mathrm{~h}\left(\Delta \mathrm{T}_{1}\right)$ or $24 \mathrm{~h}$ after transfusion $\left(\Delta \mathrm{T}_{24}\right)$, as shown in Figure 2. Syndecan-1 endothelial marker was significantly higher in the sexmismatched transfusion group compared to the sexmatched transfusion group at $\Delta \mathrm{T}_{24}(p$ value $=0.04)$. Similarly, sTM of the sex-mismatched transfusion group was significantly increased at $\Delta \mathrm{T}_{24}$ as compared to the sexmatched transfusion group $(p$ value $=0.01)$. sICAM-1 and vWF:Ag showed no significant difference between the two groups.

\section{Effect of Sex-Mismatched Transfusion on Mediators of} Endothelial Activation

Mediators that precipitate endothelial activation are shown in online supplementary Figure 1. Median levels of TNFa showed no difference over time within the sexmatched transfusion group ( $p$ value $=0.80$ ), while it tended to increase within the sex-mismatched transfusion group from $10.88 \mathrm{pg} / \mathrm{mL}$ (IQR, 7.54-13.61) at $\mathrm{T}_{0}$ to 12.54 $\mathrm{pg} / \mathrm{mL}(\mathrm{IQR}, 8.49-14.51)$ at $\mathrm{T}_{24}(p$ value $=0.06)$. The differences between the two groups (sex-matched transfusion and sex-mismatched transfusion) with regards to the presence of post-transfusion endothelial activation mediators are shown in online supplementary Figure 2. Levels of IL-6 showed no difference at $\Delta \mathrm{T}_{1}(p$ values $=0.47)$ but showed a marginally significant increase at $\Delta \mathrm{T}_{24}$ in the sex-mismatched group when compared to the sexmatched group $(p$ values $=0.05)$.

\section{Relationship between Storage Duration and \\ Endothelial Activation Markers}

Correlations between storage duration and endothelial activation markers were tested for all patients as well as for the study groups to assess if storage duration affects the differences between sex-matched and sex-mismatched groups (online supplementary Table 2). Endothelial activation markers did not correlate with storage duration.

\section{Discussion}

This study investigates the effect of donor-recipient, sex-mismatched transfusion on endothelial activation markers. Results showed that sex-mismatched transfusion was associated with increases in syndecan-1 and sTM levels compared to sex-matched transfusion. The percentage of vWF:Ag increased over time in both study groups, reaching statistical significance only in the sexmismatched transfusion group. These findings suggest that endothelial activation may play a role in the previously observed relationship between increased mortality and sex-mismatched transfusion [7-12].

Syndecan-1 and sTM elevations following sex-mismatched transfusion may indicate endothelial glycocalyx breakdown. The glycocalyx is a carbohydrate-rich layer with anti-adhesive and anticoagulant characteristics, covering the luminal side of endothelial cells [29]. Syndecan-1 is the main proteoglycan constituent of the glycocalyx. Thrombomodulin is an integral protein and also part of superficial glycocalyx but is embedded deeper within the endothelial cells [30]. Hence, the release of syndecan-1 in the circulation may reflect superficial damage to the endothelial glycocalyx, and TM shedding may reflect the disruption of the glycocalyx and endothelial cells [31]. In either case, circulating levels of syndecan-1 and sTM proportionally represent the degree of damage to the glycocalyx and/or endothelial cells [30]. It has been demonstrated that high levels of syndecan-1 and sTM are significant predictors of in-hospital mortality for critically ill patients [31-33]. This is in conjunction with findings from this study, suggesting that blood from sex-mismatched donors transfused to critically ill patients may result in more glycocalyx breakdown followed by endothelial disruption compared to sex-matched transfusions. As a consequence, glycocalyx disruption decreases the endothelial cell barrier, leading to edema and enhanced coagulation response, which may mediate organ failure, and eventually death [32]. This may explain the high mortality rate of sex-mismatched transfusion described by other studies [7-12].

Despite the relatively small difference in syndecan-1 and sTM between sex-matched and sex-mismatched groups, a recent study has related such relatively minor changes to disease severity [34]. In addition, all of the changes noted in the current study pointed towards the same direction, which is endothelial activation associated with sex-mismatched transfusions. Not to mention, these small differences were already found following a single RBC transfusion. Whether multiple RBC units would yield greater differences remains to be determined. Another possible explanation for the decline of the soluble syndecan-1 and sTM levels in sex-matched transfusion might be related to the natural course of these markers during an ICU stay. To clarify, sexmatched group is protective, or relatively protective, and the sex-mismatched transfusion "prevents" this natural decline.

The percentage of vWF:Ag was already increased prior to transfusion and increased further over time following $\mathrm{RBC}$ transfusion. During endothelial activation or in case of inflammation, vWF is released substantially by endothelial cells $[35,36]$. Thereby, the high vWF:Ag level probably reflects an already activated endothelial cell re- 
sponse in this cohort of critically ill patients, as found before $[37,38]$. However, as there was no difference between sex-matched and sex-mismatched recipients, $\mathrm{vWF}$ does not appear to be influenced by donor sex.

It has been postulated that free hemoglobin and free heme are associated with adverse outcome of RBC transfusion $[23,24,39]$. Previous studies evaluating donor sex on the RBC storage quality observed that male sex was strongly associated with storage hemolysis, suggesting that donor sex may cause post-transfusion intravascular hemolysis in the recipient $[40,41]$. However, in this study, there were no differences in free hemoglobin and free heme between the two groups suggesting that this is not a relevant mechanism in sex-mismatched transfusion, at least not following a single RBC transfusion. Also, changes in pro-inflammatory markers were small. Of note, a small difference between the sex-matched and sex-mismatched groups in IL-6 levels was observed. It is unclear whether these small differences impact clinical outcome of sex-mismatched transfusion.

The impact of storage duration on development of post-transfusion outcomes has been a controversial and much disputed subject within the field of blood transfusion [5, 42-45]. The current study assessed the relationship between endothelial markers and storage duration. However, no significant association was found.

Currently, there is no established mechanism to explain how sex-mismatched blood transfusion results in adverse outcomes of critically ill patients. One hypothesis is related to the residual plasma in the $\mathrm{RBC}$ products, which can cause transfusion-related acute lung injury (TRALI) [46, 47]. Female sex is a well-established risk factor for TRALI for plasma transfusion [48-50]. Exclusion of females from plasma donation has led to a lower incidence of TRALI $[49,51]$. In line with this explanation, a recent cohort study showed that male recipients of RBCs from female donors who had been pregnant had a higher risk of mortality than those receiving RBCs either from female donors who had never been pregnant or from male donors [52]. Another hypothesis, which we postulate, is a high proportion of young RBCs in female donor blood, which may have immunomodulatory effects [53].

A strength of the current study is that patients randomly received the transfusion product, and the caregivers are not aware of donor sex, rendering this a doubleblinded study. However, the current study is subject to several limitations. This is an observational study, therefore changes to endothelial activation and pro-inflammatory markers may be due to residual confounding that were not captured. Additionally, this study is subject to a risk of finding false-positive results (type 1 error) due to uncontrolled multiplicity in the statistical comparisons. The two groups of sex-matched and sex-mismatched were compared in four endothelial activation markers and another four mediators of endothelial activation. However, the $p$ value was not corrected for these multiple comparisons. Therefore, it is important to bear in mind that this is an explorative work raising a safety signal that should be considered cautiously. Another limitation is that this study featured a limited cohort from one singular setting, which hampers extrapolation to other sites. Some of the changes in the levels of these factors did not reach statistical significance, suggesting a too small sample size. However, all changes point towards the same direction of activation of endothelium by sex-mismatched transfusion.

In conclusion, sex-mismatched transfusion is associated with higher levels of circulating syndecan- 1 and sTM levels compared to sex-matched transfusion in ICU patients. Notwithstanding the small differences and the likelihood of confounding in this study, increased endothelial activation markers may be a relevant mechanism mediating the association between sex-mismatched transfusion and increased mortality as found in other studies. As matching the gender of RBC donor with the recipient will have consequences for ensuring adequate blood supply with minimum waste, results need to be confirmed in other studies prior to changes in transfusion practices.

\section{Acknowledgements}

The authors would like to thank statisticians at the division of Statistics Consultation, the Department of Epidemiology and Data Science-Methodology at Amsterdam UMC for their help in verifying the statistical analyses. We would also like to acknowledge the staff of Sanquin and the blood banks of Amsterdam UMC for their help in retrieving blood donor information. Abdulrahman Alshalani is supported by the King Saud University and the Saudi Arabian Cultural Bureau in the Netherlands.

\section{Statement of Ethics}

Ethical approval of this study was obtained from the Medical Ethical Committee of the Amsterdam Medical Centre, Amsterdam (NTR 6596; NL61833.018.17). Written informed consent was obtained from all participants or their legal representatives.

\section{Conflict of Interest Statement}

The authors have no conflicts of interest to declare.

\section{Funding Sources}

This article did not receive sponsorship for publication. 


\section{Author Contributions}

A.A. and N.P.J. conceived and planned the study. L.v.M. and M.B. collected data for the study. A.A. performed data analyses and drafted the manuscript. L.v.M., M.B., R.v.B., J.P.A., and N.P.J. provided critical feedback and helped shape the manuscript. All authors read and approved the final manuscript.

\section{Data Availability Statement}

The datasets generated and analyzed during the current study are not publicly available due to patient and blood donor privacy but are available from the corresponding author on reasonable request.

\section{References}

1 Vincent JL, Baron JF, Reinhart K, Gattinoni L, Thijs L, Webb A, et al. Anemia and blood transfusion in critically ill patients. Jama. 2002 Sep 25;288(12):1499-507.

2 Corwin HL, Gettinger A, Pearl RG, Fink MP, Levy MM, Abraham E, et al. The CRIT Study: Anemia and blood transfusion in the critically ill - current clinical practice in the United States. Crit Care Med. 2004 Jan;32(1):39-52.

3 Vincent JL, Jaschinski U, Wittebole X, Lefrant JY, Jakob SM, Almekhlafi GA, et al. Worldwide audit of blood transfusion practice in critically ill patients. Crit Care. 2018 Apr 19; 22(1):102.

4 Marik PE, Corwin HL. Efficacy of red blood cell transfusion in the critically ill: a systematic review of the literature. Crit Care Med. 2008 Sep;36(9):2667-74.

5 Lacroix J, Hebert PC, Fergusson DA, Tinmouth A, Cook DJ, Marshall JC, et al. Age of transfused blood in critically ill adults. $\mathrm{N}$ Engl J Med. 2015 Apr 9;372(15):1410-8.

6 Muszynski JA, Spinella PC, Cholette JM, Acker JP, Hall MW, Juffermans NP, et al. Transfusion-related immunomodulation: review of the literature and implications for pediatric critical illness. Transfusion. 2017 Jan;57(1): 195-206.

7 Middelburg RA, Briët E, van der Bom JG. Mortality after transfusions, relation to donor sex. Vox Sang. 2011 Oct;101(3):221-9.

8 Bjursten H, Dardashti A, Björk J, Wierup P, Algotsson L, Ederoth P. Transfusion of sexmismatched and non-leukocyte-depleted red blood cells in cardiac surgery increases mortality. J Thorac Cardiovasc Surg. 2016 Jul; 152(1):223-e1.

9 Chasse M, McIntyre L, English SW, Tinmouth A, Knoll G, Wolfe D, et al. Effect of Blood Donor Characteristics on Transfusion Outcomes: A Systematic Review and MetaAnalysis. Transfus Med Rev. 2016 Apr;30(2): 69-80.

10 Chasse M, Tinmouth A, English SW, Acker JP, Wilson K, Knoll G, et al. Association of Blood Donor Age and Sex With Recipient Survival After Red Blood Cell Transfusion. JAMA Intern Med. 2016 Sep 1;176(9):1307-14.

11 Heddle NM, Cook RJ, Liu Y, Zeller M, Barty $\mathrm{R}$, Acker JP, et al. The association between blood donor sex and age and transfusion recipient mortality: an exploratory analysis. Transfusion. 2019 Feb;59(2):482-91.

12 Roubinian NH, Westlake M, St Lezin EM, Edgren G, Brambilla DJ, Lee C, et al. Association of donor age, body mass index, hemoglobin, and smoking status with in-hospital mortality and length of stay among red blood celltransfused recipients. Transfusion. $2019 \mathrm{Nov}$ 59(11):3362-70.
13 Edgren G, Ullum H, Rostgaard K, Erikstrup C, Sartipy U, Holzmann MJ, et al. Association of Donor Age and Sex With Survival of Patients Receiving Transfusions. JAMA Intern Med. 2017 Jun 1;177(6):854-60.

14 Ridker PM, Brown NJ, Vaughan DE, Harrison DG, Mehta JL. Established and emerging plasma biomarkers in the prediction of first atherothrombotic events. Circulation. 2004 Jun 29;109(25 Suppl 1):Iv6-19.

15 Deanfield JE, Halcox JP, Rabelink TJ. Endothelial function and dysfunction: testing and clinical relevance. Circulation. 2007 Mar 13; 115(10):1285-95.

16 van Ierssel SH, Jorens PG, Van Craenenbroeck EM, Conraads VM. The Endothelium, A Protagonist in the Pathophysiology of Critical Illness: Focus on Cellular Markers. Biomed Res Int. 2014;2014:985813.

17 Ostrowski SR, Haase N, Müller RB, Møller MH, Pott FC, Perner A, et al. Association between biomarkers of endothelial injury and hypocoagulability in patients with severe sepsis: a prospective study. Critical care (London, England). 2015;19(1):191-1.

18 Hughes CG, Pandharipande PP, Thompson JL, Chandrasekhar R, Ware LB, Ely EW, et al. Endothelial Activation and Blood-Brain Barrier Injury as Risk Factors for Delirium in Critically Ill Patients. Crit Care Med. 2016 Sep;44(9):e809-17.

19 Larsen AM, Leinøe EB, Johansson PI, Birgens $\mathrm{H}$, Ostrowski SR. Haemostatic function and biomarkers of endothelial damage before and after RBC transfusion in patients with haematologic disease. Vox Sang. 2015 Jul;109(1): 52-61.

20 Kipkeu BJ, Almizraq R, Branch DR, Acker JP, Holovati JL. Red cell supernatant effects on endothelial cell function and innate immune activation is influenced by donor age and sex. Voxs. 2018;13(4):446-59.

21 Cata JP, Wang H, Gottumukkala V, Reuben J, Sessler DI. Inflammatory response, immunosuppression, and cancer recurrence after perioperative blood transfusions. Br J Anaesth. 2013 May;110(5):690-701.

22 Stenvinkel P. Endothelial dysfunction and inflammation-is there a link? Nephrol Dial Transplant. 2001 Oct;16(10):1968-71.

23 Wagener FA, Feldman E, de Witte T, Abraham NG. Heme induces the expression of adhesion molecules ICAM-1, VCAM-1, and E selectin in vascular endothelial cells. Proc Soc Exp Biol Med. 1997 Dec;216(3):456-63.

24 Balla J, Vercellotti GM, Nath K, Yachie A, Nagy E, Eaton JW, et al. Haem, haem oxygenase and ferritin in vascular endothelial cell injury. Nephrol Dial Transplant. 2003 Jul; 18(Suppl 5):v8-12.
25 Kartikasari AE, Georgiou NA, Visseren FL, van Kats-Renaud $H$, van Asbeck BS, Marx JJ. Endothelial activation and induction of monocyte adhesion by nontransferrin-bound iron present in human sera. FASEB J. 2006 Feb;20(2):353-5.

26 Kuo KL, Hung SC, Lin YP, Tang CF, Lee TS, Lin CP, et al. Intravenous ferric chloride hexahydrate supplementation induced endothelial dysfunction and increased cardiovascular risk among hemodialysis patients. PLoS One. 2012;7(12):e50295.

27 Kucukal E, Ilich A, Key NS, Little JA, Gurkan UA. Red Blood Cell Adhesion to Heme-Activated Endothelial Cells Reflects Clinical Phenotype in Sickle Cell Disease. Am J Hematol. 2018 Jun 15:10.1002/ajh.25159.

28 Mohanty S, Codell R. Sensitivity analysis methods for identifying influential parameters in a problem with a large number of random variables. 2002:363-74.

29 Reitsma S, Slaaf DW, Vink H, van Zandvoort MA, oude Egbrink MG. The endothelial glycocalyx: composition, functions, and visualization. Pflugers Arch. 2007;454(3):345-59.

30 Schott U, Solomon C, Fries D, Bentzer P. The endothelial glycocalyx and its disruption, protection and regeneration: a narrative review. Scandinavian journal of trauma, resuscitation and emergency medicine. $2016 \mathrm{Apr}$ 12;24:48.

31 Johansen ME, Johansson PI, Ostrowski SR, Bestle MH, Hein L, Jensen AL, et al. Profound endothelial damage predicts impending organ failure and death in sepsis. Seminars in thrombosis and hemostasis. 2015 Feb;41(1): 16-25.

32 Johansson PI, Stensballe J, Rasmussen LS, Ostrowski SR. A high admission syndecan-1 level, a marker of endothelial glycocalyx degradation, is associated with inflammation, protein $\mathrm{C}$ depletion, fibrinolysis, and increased mortality in trauma patients. Ann Surg. 2011 Aug;254(2):194-200.

33 Neves FM, Meneses GC, Sousa NE, Menezes RR, Parahyba MC, Martins AM, et al. Syndecan-1 in Acute Decompensated Heart Failure--Association With Renal Function and Mortality. Circulation journal : official journal of the Japanese Circulation Society. 2015; 79(7):1511-9.

$34 \mathrm{Lu} \mathrm{R}$, Sui J, Zheng XL. Elevated plasma levels of syndecan-1 and soluble thrombomodulin predict adverse outcomes in thrombotic thrombocytopenic purpura. Blood Adv. 2020 Nov 10;4(21):5378-88.

35 Cross LJ, Matthay MA. Biomarkers in acute lung injury: insights into the pathogenesis of acute lung injury. Crit Care Clin. 2011 Apr; 27(2):355-77. 
36 Chen J, Chung DW. Inflammation, von Willebrand factor, and ADAMTS13. Blood. 2018 Jul 12;132(2):141-7.

37 Ware LB, Conner ER, Matthay MA. von Willebrand factor antigen is an independent marker of poor outcome in patients with early acute lung injury. Crit Care Med. 2001 Dec; 29(12):2325-31.

38 Ware LB, Eisner MD, Thompson BT, Parsons PE, Matthay MA. Significance of von Willebrand factor in septic and nonseptic patients with acute lung injury. Am J Respir Crit Care Med. 2004 Oct 1;170(7):766-72.

39 Hod EA, Zhang N, Sokol SA, Wojczyk BS, Francis RO, Ansaldi D, et al. Transfusion of red blood cells after prolonged storage produces harmful effects that are mediated by iron and inflammation. Blood. 2010 May 27, 115(21):4284-92.

40 Kanias T, Sinchar D, Osei-Hwedieh D, Baust JJ, Jordan A, Zimring JC, et al. Testosteronedependent sex differences in red blood cell hemolysis in storage, stress, and disease. Transfusion. 2016 Oct;56(10):2571-83.

41 Kanias T, Lanteri MC, Page GP, Guo Y, Endres SM, Stone M, et al. Ethnicity, sex, and age are determinants of red blood cell storage and stress hemolysis: results of the REDS-III RBCOmics study. Blood Adv. 2017 Jun 27;1(15): 1132-41.
42 Triulzi DJ, Yazer MH. Clinical studies of the effect of blood storage on patient outcomes. Transfus Apher Sci. 2010 Aug;43(1):95-106.

43 Wang D, Sun J, Solomon SB, Klein HG, Natanson C. Transfusion of older stored blood and risk of death: a meta-analysis. Transfusion. 2012 Jun;52(6):1184-95.

44 Middelburg RA, van de Watering LM, Briët E, van der Bom JG. Storage Time of Red Blood Cells and Mortality of Transfusion Recipients. Transfus Med Rev. 2013;27(1):36-43.

45 Steiner ME, Ness PM, Assmann SF, Triulzi DJ, Sloan SR, Delaney M, et al. Effects of redcell storage duration on patients undergoing cardiac surgery. N Engl J Med. 2015 Apr 9; 372(15):1419-29.

46 Win N, Chapman CE, Bowles KM, Green A, Bradley S, Edmondson D, et al. How much residual plasma may cause TRALI?. Transfusion medicine (Oxford, England). 2008 Oct; 18(5):276-80.

47 Vlaar APJ, Hofstra JJ, Determann RM, Veelo DP, Paulus F, Kulik W, et al. The incidence, risk factors, and outcome of transfusion-related acute lung injury in a cohort of cardiac surgery patients: a prospective nested casecontrol study. Blood. 2011;117(16):4218-25.

48 Eder AF, Herron R, Strupp A, Dy B, Notari EP, Chambers LA, et al. Transfusion-related acute lung injury surveillance (2003-2005) and the potential impact of the selective use of plasma from male donors in the American Red Cross. Transfusion. 2007 Apr;47(4):599607.

49 Chapman CE, Stainsby D, Jones H, Love E, Massey E, Win N, et al. Ten years of hemovigilance reports of transfusion-related acute lung injury in the United Kingdom and the impact of preferential use of male donor plasma. Transfusion. 2009 Mar;49(3):440-52.

50 Toy P, Gajic O, Bacchetti P, Looney MR, Gropper MA, Hubmayr R, et al. Transfusionrelated acute lung injury: incidence and risk factors. Blood. 2012 Feb 16;119(7):1757-67.

51 Chapman CE, Williamson LM. National Blood Service TRALI Reduction Policies: Implementation and Effect. Transfus Med Hemother. 2008;35(2):93-6.

52 Caram-Deelder C, Kreuger AL, Evers D, de Vooght KMK, van de Kerkhof D, Visser O, et al. Association of Blood Transfusion From Female Donors With and Without a History of Pregnancy With Mortality Among Male and Female Transfusion Recipients. Jama. 2017 Oct 17;318(15):1471-8.

53 Alshalani A, Li W, Juffermans NP, Seghatchian J, Acker JP. Biological mechanisms implicated in adverse outcomes of sex mismatched transfusions. Transfus Apher Sci. 2019 Jun; 58(3):351-6. 